\title{
An unusual penetrating injury of the back: retroperitoneal hematoma from a glass stabbing injury: a case report
}

\author{
Dongwoo Yu, Ikchan Jeon, Sang Woo Kim \\ Department of Neurosurgery, Yeungnam University Hospital, Yeungnam University College of Medicine, Daegu, South Korea \\ Correspondence to: Dongwoo Yu, MD. Department of Neurosurgery Yeungnam University College of Medicine, 170, Hyeonchung street, Nam-Gu, \\ Daegu, South Korea. Email: ydwnss@yu.ac.kr.
}

\begin{abstract}
In stab injury of the back visceral or vascular injuries are more uncommon than anterior abdominal stab injuries. The authors report the case of a 52-year-old man who presented to the emergency center with glass fragments lodged in his back after falling on a glass door on his back. On a retroperitoneal computed tomography (CT) scan, two foreign bodies were detected in left paraspinal and psoas muscles. Furthermore, hematoma with active bleeding was seen in the retroperitoneal cavity. He was referred to a general surgeon for retroperitoneal active bleeding, but emergency laparotomy was not deemed necessary considering the patient's stable condition in terms of vital signs, the level of hemoglobin, and the amount of bleeding. Therefore, we performed conservative treatment, such as packed cell transfusion and back compression, after removing the glass fragment through the posterior approach. The paravertebral muscle was dissected through the open wound, the tip of the piece of glass was accessible. The piece of glass was carefully removed, and there was no active bleeding. The postoperative CT scan showed continued active bleeding and increased retroperitoneal hematoma, but the patient's vital signs were stable. Conservative treatment was administered continuously, a follow-up CT scan taken a month later showed hematoma resolution and no more dye leakage. If the patient's vital signs are stable and the patient is neurologically intact, conservative treatment may be prioritized without laparotomy.
\end{abstract}

Keywords: Penetrating injury; stab wound; retroperitoneal hematoma; foreign body; case report

Submitted May 01, 2021. Accepted for publication Jul 07, 2021.

doi: 10.21037/apm-21-1097

View this article at: https://dx.doi.org/10.21037/apm-21-1097

\section{Introduction}

In stab injury of the back, retroperitoneal structures are well protected by thick back muscles, ribs, and the vertebral column; thus, visceral or vascular injuries are more uncommon than anterior abdominal stab injuries (1). It is necessary, however, to carefully evaluate the retroperitoneal area in a stab injury of the back because the retroperitoneal area contains many critical organs, including the aorta, vena cava, kidneys, ureter, pancreas, and colon (2). However, it is uncommon for a patient to visit to the hospital with a foreign body lodged in the back. In such cases, the removal of the foreign body is necessary while being often challenging as the removal can lead to the risk of hemodynamic problem or neurological compromise.
We report an uncommon case of a 52-year-old male patient who presented to the emergency center with a stab injury on the back with a foreign body lodged in his paraspinal and psoas muscles. We present the following case in accordance with the CARE reporting checklist (available at https://apm. amegroups.com/article/view/10.21037/apm-21-1097/rc).

\section{Case presentation}

A 52-year-old male patient was taken to the emergency center with a stab injury in his back. An hour before the visit to the emergency center, he was pushed by someone in the bar and fell over the glass door. As he fell, the glass door shattered, and at the time of his visit, he was bleeding from a wound on his back. Evaluation of his back demonstrated a 

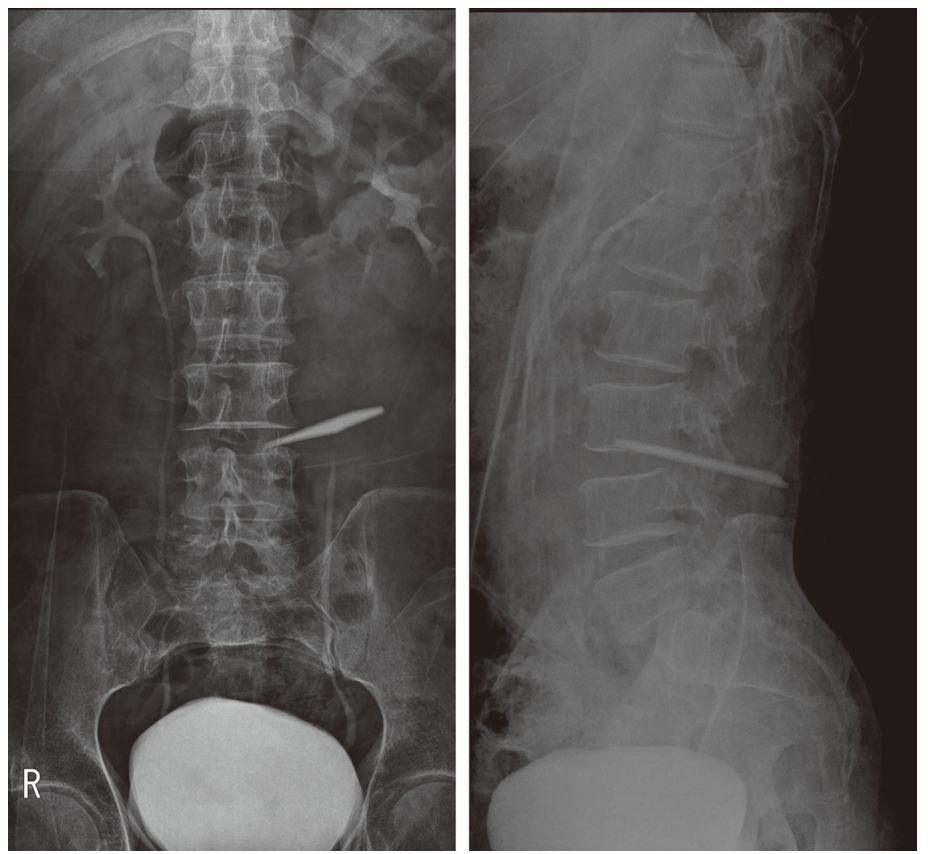

Figure 1 Plain lumbar spine X-ray. A piece of foreign body detected between the right L3 and L4 transverse processes. The tip of the foreign body was located anterior body depth of L3 vertebra.

linear 4-cm-long stab wound in the lower left paravertebral lumbar area. Although there was no active massive bleeding from the wound, moderate swelling around the wound was noted. We could see a glass-like foreign body on the surface of wound.

On examination at the emergency center visit, he was neurologically intact. He scored 15 points on the Glasgow Coma Scale. He had 5/5 motor strength in all muscle groups in both extremities, and his sensory function was also intact in all dermatomes. His initial vital signs were as follows: blood pressure $100 / 60 \mathrm{mmHg}$, temperature $36.1{ }^{\circ} \mathrm{C}$, heart rate 72 beats $/ \mathrm{min}$, and respiratory rate 20 breaths $/ \mathrm{min}$. His initial hemoglobin was $12.4 \mathrm{~g} / \mathrm{dL}$, erythrocyte sedimentation rate (ESR) was $2 \mathrm{~mm} / \mathrm{H}$, and C-reactive protein (CRP) level was $0.19 \mathrm{mg} / \mathrm{dL}$.

The plain lumbar spine $\mathrm{X}$-ray showed a foreign body detected between the right L3 and L4 transverse process. The tip of the foreign body was located anterior body depth of L3 vertebra (Figure 1). He underwent an additional retroperitoneal computed tomography $(\mathrm{CT})$. On CT scan, two foreign bodies measuring $78 \mathrm{~mm} \times 35 \mathrm{~mm} \times 4.5 \mathrm{~mm}$ and $33 \mathrm{~mm} \times 20 \mathrm{~mm} \times 4.5 \mathrm{~mm}$ were seen in left paraspinal and psoas muscles. Furthermore, hematoma with active bleeding was seen in the retroperitoneal cavity (Figure 2).
A piece of superficially lodged glass was removed at the emergency center itself, but it was difficult to access the other piece of glass which was lodged more deeply into the surface. The patient was taken to the operating room for foreign body removal and irrigation. Through the open wound, the paravertebral muscle was dissected, and we could access the tip of the piece of glass, which was then carefully removed with moderate bleeding (Figure 3). After the bleeding was brought under control, irrigation was done multiple times. Although there was no massive bleeding on operation, systolic blood pressure dropped to 70 $80 \mathrm{mmHg}$ during the operation, and three units of packed red blood cell transfusions were given. On the postoperative retroperitoneal CT scan, the foreign body was confirmed as removed without any remnant pieces, but there was still active bleeding, and the amount of retroperitoneal hematoma increased. Immediate postoperative vital signs were blood pressure $90 / 60 \mathrm{mmHg}$, temperature $35.9^{\circ} \mathrm{C}$, heart rate 90 beats/min, and respiratory rate 18 breaths/min. The hemoglobin level was $9.5 \mathrm{~g} / \mathrm{dL}$, and we transfused another two units of packed red blood cells. The patient was intensively monitored in the intensive care unit, and fortunately, blood pressure and hemoglobin levels did not 

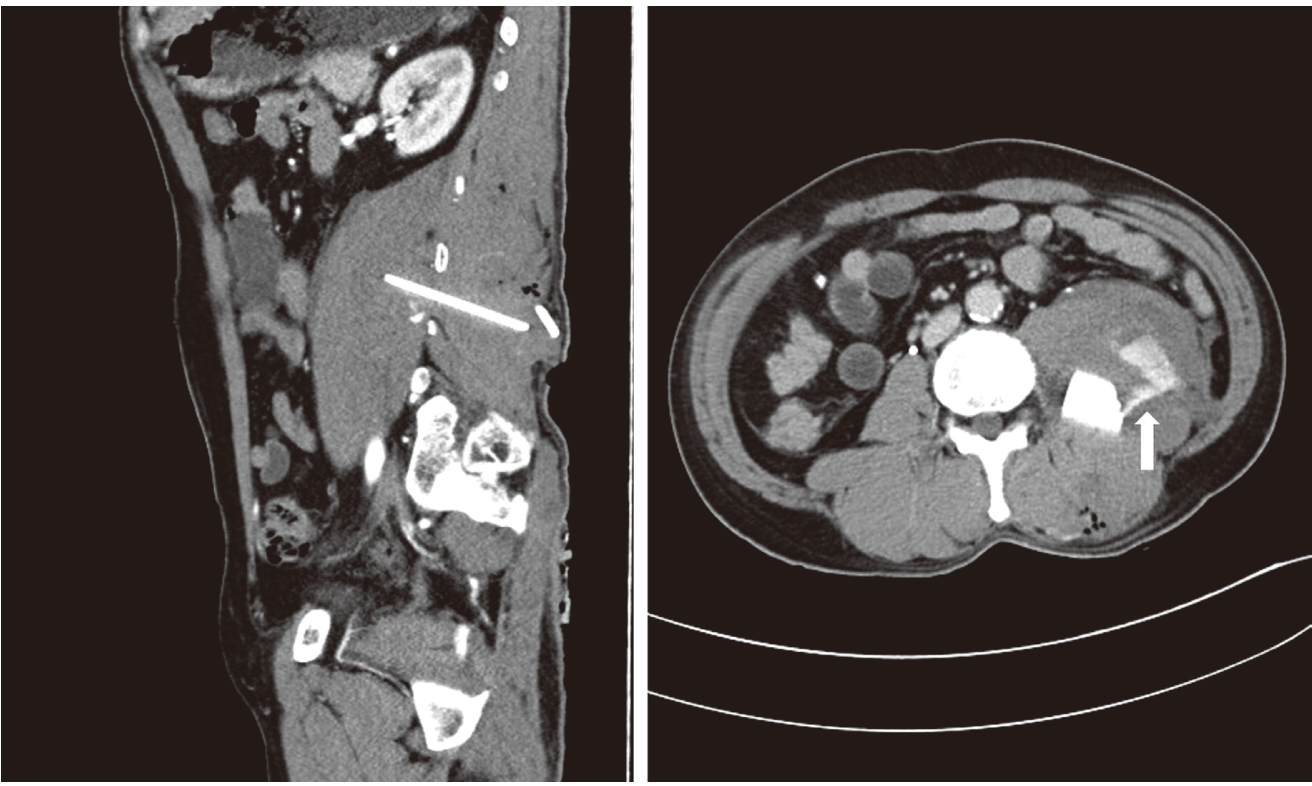

Figure 2 On retroperitoneal computed tomography scan, two foreign bodies measuring $78 \mathrm{~mm} \times 35 \mathrm{~mm} \times 4.5 \mathrm{~mm}$ and $33 \mathrm{~mm} \times 20 \mathrm{~mm} \times$ $4.5 \mathrm{~mm}$ were seen in the left paraspinal and psoas muscles with a retroperitoneal hematoma. The arrow indicates retroperitoneal hematoma with contrast medium extravasation.
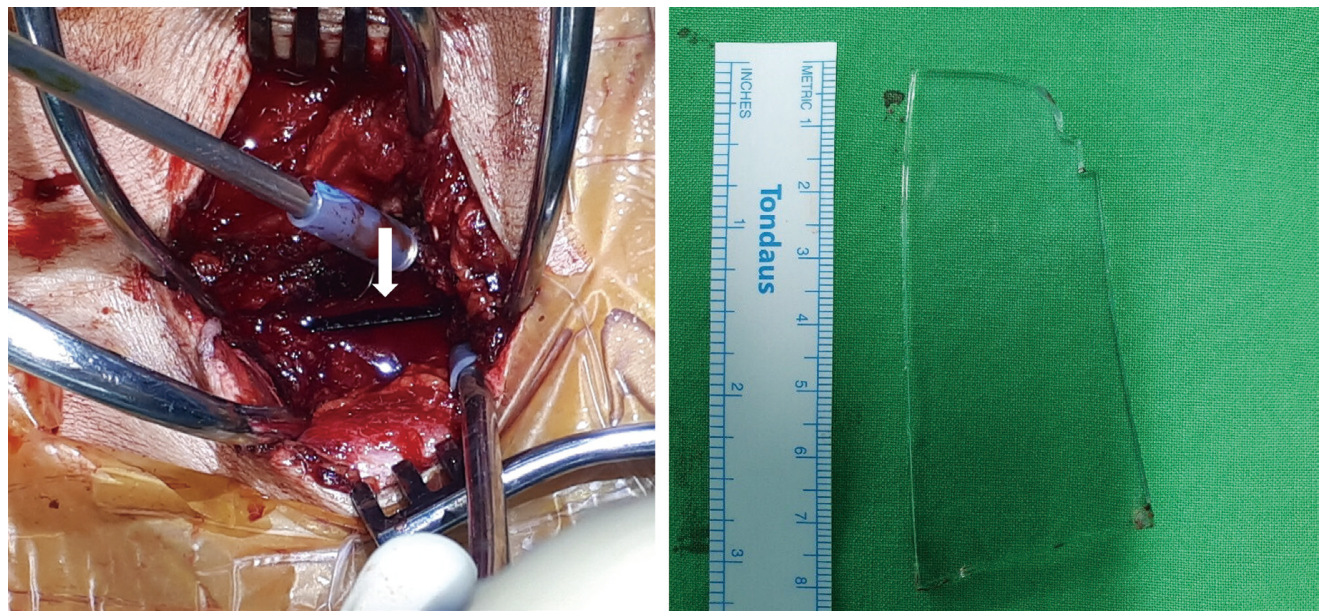

Figure 3 The tip of a piece of glass was found between the paraspinal muscles (arrow), and it was removed.

decrease further. He was taken to the general ward and started on antibiotics for 2 weeks. Then, he was discharged without any infection or unresolved wounds. On a CT scan that performed 1 month after discharge, retroperitoneal hematoma appeared almost resolved, and his ESR/CRP levels had also normalized (Figure 4).

All procedures performed in this study were in accordance with the ethical standards of the Institutional Review Board of our Medical Center (IRB No. 2020-08014) and with the Helsinki Declaration (as revised in 2013). Written informed consent was obtained from the patient for publication of this case report and any accompanying images. A copy of the written consent is available for review by the editorial office of this journal. 

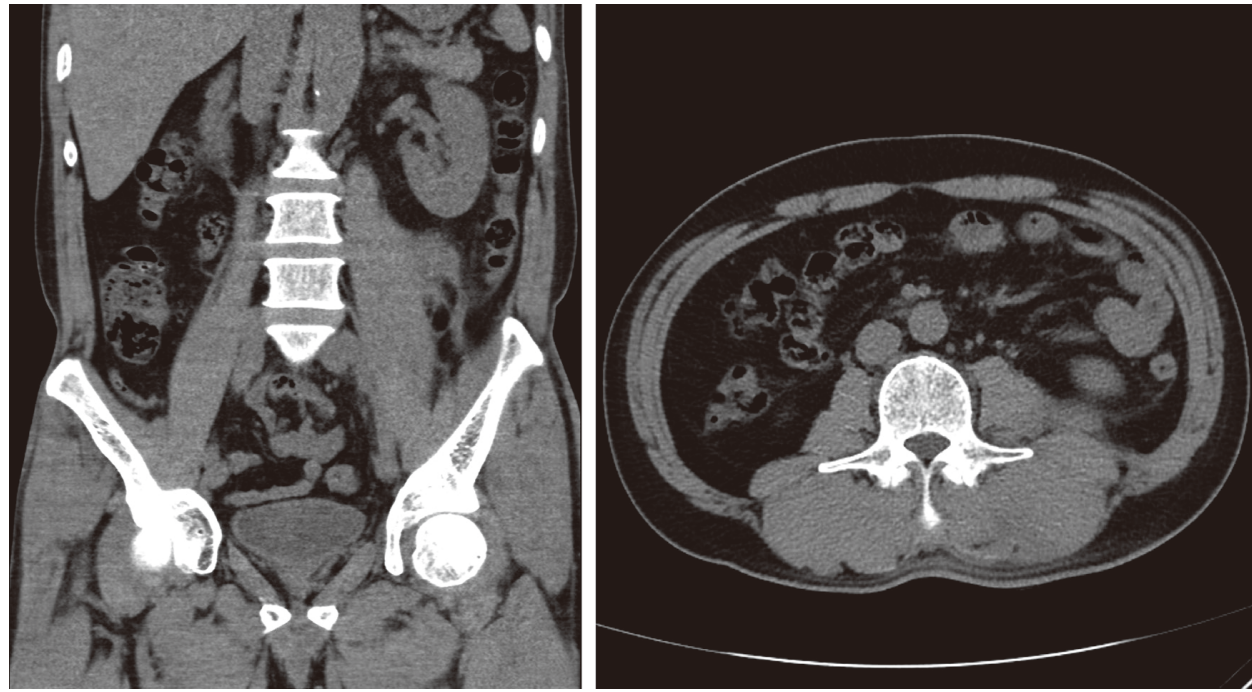

Figure 4 Retroperitoneal computed tomography scan on 6 weeks after the operation revealed retroperitoneal hematoma was almost resolved.

\section{Discussion}

Stab injuries to the back present a serious clinical challenge to trauma surgeons because the extent of injury is difficult to evaluate, particularly when the injury is confined to the retroperitoneum (3). Thus, patients with stab injuries to the back need systematic evaluation. Generally, penetrating injuries on the back pose lower risk of fatal damage than anterior abdominal penetrating injuries because the back muscles shield many vital organs and absorb much of the injury. However, in our patient, a piece of glass passed through the paraspinal muscles and caused retroperitoneal hemorrhage by damage to the psoas muscle. We herein reported an experience of treating a patient with retroperitoneal hemorrhage due to a penetrating injury to the back.

Abdominal CT is a reliable diagnostic tool for evaluating a penetrating injury to the back. Several studies recommend contrast-enhanced CT scan to detect significant visceral or vascular injuries $(4,5)$. Contrast-enhanced CT has low morbidity in hemodynamically stable patients and rapidly reveals the location and extent of organ damage (6). In our case, initial retroperitoneal CT scan showed that the end of the glass was stabbing the left psoas muscle, and we could identify dye leakage suggesting that active bleeding was occurring. The patient was evaluated by a general surgeon for retroperitoneal active bleeding, but emergency laparotomy was not considered necessary given the patient's stable vital signs, the level of hemoglobin, and the amount of bleeding. Therefore, we performed conservative treatment involving packed cell transfusion and back compression after removing the glass fragment through the posterior approach. Postoperative retroperitoneal CT scan showed that dye leakage persisted despite the patient's vital sign being stable. Conservative treatment was continued, and few days later, the follow-up CT scan showed hematoma resolution confirmed by the absence of dye leakage. During conservative treatment, the patient did not complain of compressive femoral neuropathy like lower limb sensory numbness or paresthesia or motor weakness. Sahu et al. (7) reported that among 78 patients with retroperitoneal hematoma, most were successfully managed medically alone.

Treatment of iliopsoas muscle hematoma depends on the hemodynamic status, volume of hematoma, speed of onset, and neurological deficit (8). In this case, there was active bleeding but we treated him with conservative management involving transfusion and bed rest. If the patient had showed any neurological symptoms or unstable vitals, we would have considered open laparotomy or arterial embolization. In addition, preventing infection from the foreign body is important. Intraoperatively, irrigation was done multiple times, and IV antibiotics (mebapenem) were administered for 2 weeks. There was no sign of any infection and ESR/ CRP levels had gradually normalized.

We reported a rare case of retroperitoneal hemorrhage by 
penetrating injury of the back. If the patient's vital signs are stable and the patient is neurologically intact, conservative treatment may be prioritized without laparotomy.

\section{Acknowledgments}

Funding: This work was supported by the National Research Foundation of Korea (NRF) and a Grant funded by the Korea Government (NRF-2019M3E5D1A02068142).

\section{Footnote}

Reporting Checklist: The authors have completed the CARE reporting checklist. Available at https://apm.amegroups. com/article/view/10.21037/apm-21-1097/rc

Conflicts of Interest: All authors have completed the ICMJE uniform disclosure form (available at https://apm. amegroups.com/article/view/10.21037/apm-21-1097/ coif). The authors report that this work was supported by the National Research Foundation of Korea (NRF) and a Grant funded by the Korea Government (NRF2019M3E5D1A02068142). The authors have no other conflicts of interest to declare.

Ethical Statement: The authors are accountable for all aspects of the work in ensuring that questions related to the accuracy or integrity of any part of the work are appropriately investigated and resolved. All procedures performed in this study were in accordance with the ethical standards of the Institutional Review Board of our Medical Center (IRB No. 2020-08-014) and with the Helsinki Declaration (as revised in 2013). Written informed consent was obtained from the patient for publication of this case report and any accompanying images. A copy of the written consent is available for review by the editorial office of this journal.

Open Access Statement: This is an Open Access article distributed in accordance with the Creative Commons
Attribution-NonCommercial-NoDerivs 4.0 International License (CC BY-NC-ND 4.0), which permits the noncommercial replication and distribution of the article with the strict proviso that no changes or edits are made and the original work is properly cited (including links to both the formal publication through the relevant DOI and the license). See: https://creativecommons.org/licenses/by-nc-nd/4.0/.

\section{References}

1. Boyle EM Jr, Maier RV, Salazar JD, et al. Diagnosis of injuries after stab wounds to the back and flank. J Trauma 1997;42:260-5.

2. Alexander RH, Proctor HJ, American College of Surgeons Committee on Trauma. Advanced trauma life support program for physicians: ATLS. 5th ed. Chicago, IL: American College of Surgeons, 1993.

3. Fletcher TB, Setiawan H, Harrell RS, et al. Posterior abdominal stab wounds: role of CT evaluation. Radiology 1989;173:621-5.

4. Phillips T, Sclafani SJ, Goldstein A, et al. Use of the contrast-enhanced CT enema in the management of penetrating trauma to the flank and back. J Trauma 1986;26:593-601.

5. Kirton OC, Wint D, Thrasher B, et al. Stab wounds to the back and flank in the hemodynamically stable patient: a decision algorithm based on contrast-enhanced computed tomography with colonic opacification. Am J Surg 1997;173:189-93.

6. Himmelman RG, Martin M, Gilkey S, et al. Triplecontrast CT scans in penetrating back and flank trauma. J Trauma 1991;31:852-5.

7. Sahu KK, Mishra AK, Lal A, et al. Clinical spectrum, risk factors, management and outcome of patients with retroperitoneal hematoma: a retrospective analysis of 3-year experience. Expert Rev Hematol 2020;13:545-55.

8. Marquardt G, Barduzal Angles S, Leheta F, et al. Spontaneous haematoma of the iliac psoas muscle: a case report and review of the literature. Arch Orthop Trauma Surg 2002;122:109-11.
Cite this article as: Yu D, Jeon I, Kim SW. An unusual penetrating injury of the back: retroperitoneal hematoma from a glass stabbing injury: a case report. Ann Palliat Med 2022;11(6):2157-2161. doi: 10.21037/apm-21-1097 